\title{
Hypereosinophilic syndrome presenting as peripheral neuropathy
}

\author{
D. Bell, I.G. Mackay and B. Pentland ${ }^{1}$
}

University Department of Medicine, Royal Infirmary of Edinburgh and 'Astley Ainslie Hospital, Edinburgh, UK.

\begin{abstract}
Summary: An unusual case of hypereosinophilic syndrome is described which presented with peripheral neuropathy with no evidence of cardiac involvement. The response to steroid therapy is documented and the literature on peripheral neuropathy in hypereosinophilic syndrome is reviewed.
\end{abstract}

\section{Introduction}

Hypereosinophilic syndrome (HES) is characterized by an increase in circulating eosinophils (greater than $1.5 \times 10^{9} / 1$ ) for which there is no known cause. The central nervous system is affected in $30-50 \%$ of patients (Chusid et al., 1975; Spry et al., 1983a), and this usually consists of focal or diffuse cerebral involvement. There have been few reports of peripheral neuropathy in HES (Chusid et al., 1975; Dorfman et al., 1983) and none in which severe peripheral neuropathy was the presenting feature. We describe a patient with HES who presented with a peripheral neuropathy and review the literature on peripheral neuropathy in HES.

\section{Case report}

A 21 year old man presented in April 1983 with pain in his calves and forearms, paraesthesiae of the hands and feet and impairment in handgrip of 4 weeks duration. He had general malaise and systematic enquiry revealed an episode of amaurosis fugax 3 weeks before admission. Fifteen months previously asthma had been diagnosed but this was well controlled on salbutamol and beclomethasone inhalers. There was no history of atopy, and skin tests to various allergens including aspergillus were negative apart from a positive reaction to house dust mite. At presentation he was pyrexial and looked unwell. Cardiovascular, respiratory and abdominal examination was normal. He had weakness and wasting of all the intrinsic muscles of the hands which was more marked on the left (Figure 1). There was weakness of elbow flexion and extension bilaterally with a severe

Correspondence: D. Bell, M.B., Ch.B., M.R.C.P.(UK), Department of Medicine, Royal Infirmary, Edinburgh EH3 9YW

Accepted: 20 August 1984 left foot drop and slight distal weakness in the right leg. Sensation was impaired in a glove and stocking distribution with reduction of pinprick and light touch sensation to the level of wrists and ankles respectively. Knee, ankle and triceps jerks were absent, biceps and supinator reflexes were obtained with reinforcement and plantars were flexor. Fundoscopy was normal and there was no evidence of upper motor neurone involvement.

White cell count was $42.3 \times 10^{9} / 1$ with $29.6 \times 10^{9} / 1$ eosinophils, haemoglobin $14.5 \mathrm{~g} / \mathrm{dl}$, platelets $510 \times 10^{9} / 1$ and ESR $95 \mathrm{~mm} / \mathrm{h}$. Bone marrow aspirate revealed large numbers of eosinophils and eosinophil precursors with a less marked increase in megakaryocytes and plasma cells. Chromosomal analysis was normal and leucocyte alkaline phosphatase score was elevated at 225 .

Urinalysis and creatinine clearance were normal. Plasma alkaline phosphatase was elevated (199 IU/1) as was gamma-glutamyl transferase (205 IU/1). An isotope liver scan demonstrated moderate liver enlargement but laparoscopic liver biopsies were normal. Rose-Waaler differential factor was elevated on two occasions (1024 and 512 units) and there was a diffuse increase in immunoglobulins. Repeated urine, stool and blood cultures, were negative, as were stool microscopic examinations, screening for autoantibodies, complement and viruses, including hepatitis B surface antigen. Cerebrospinal fluid examination, electroencephalography, computed tomographic brain scan, chest X-rays, electrocardiogram, echocardiography, radionuclide ventriculography and abdominal aortography were also normal. Nerve conduction studies were performed on 3 occasions and no recordable potential could be obtained from the median nerves or the left ulnar nerve. The motor conduction velocity in the right ulnar nerve was significantly reduced on one occasion and at the lower end of the normal range on repeat testing. Sensory 


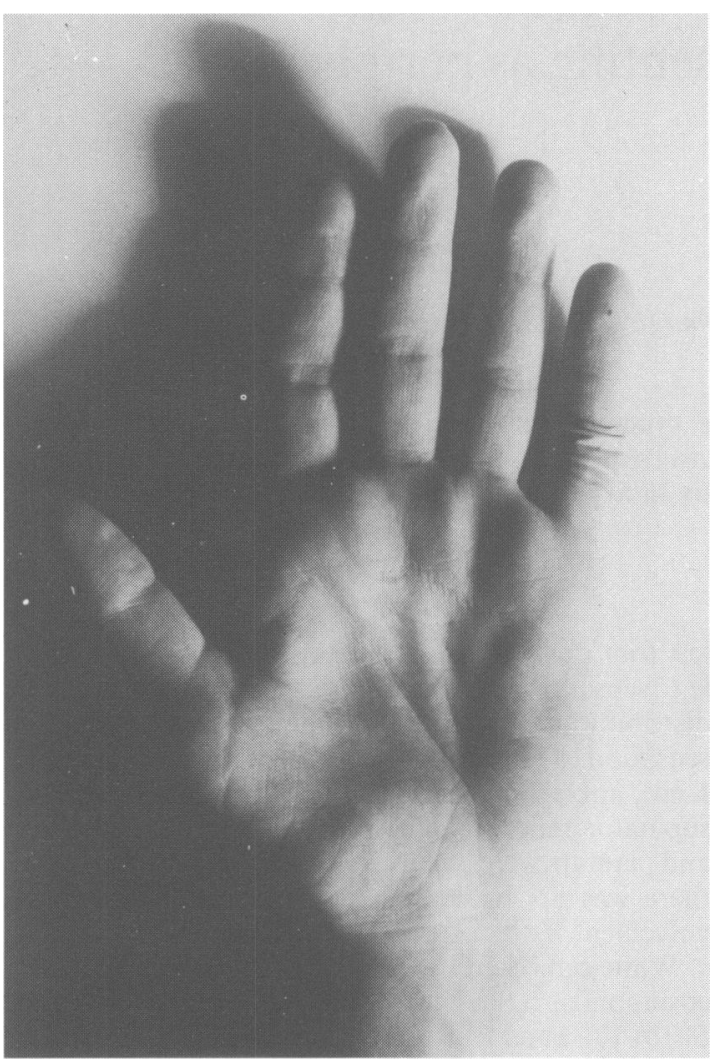

Figure 1 Photograph showing marked thenar, hypothenar and small muscle wasting in peripheral neuropathy, secondary to hypereosinophilic syndrome.

potentials were obtained on the first occasion only. The results of right ulnar nerve conduction studies are given in Table I. Autonomic function studies were performed as described by Ewing \& Clarke (1982) and these indicated parasympathetic damage. Sural nerve biopsy revealed perineural fibrosis and focal myelin degeneration but no inflammatory cell infiltrate or arteritic lesions.

One week after admission prednisolone therapy was started and his eosinophil count fell (Figure 2). During the first month his weakness increased, exercise tolerance declined and the painful paraesthesiae persisted. In May, following laparascopic liver biopsy, he had an episode of epigastric pain accompanied by a transient disturbance of liver enzymes which may have been related to enflurane anaesthesiae. The following month he became anorexic, losing $18 \mathrm{~kg}$ in weight over a 3 month period, and his abdominal pain recurred. Despite an increase in his corticosteroid therapy his general condition deteriorated such that enteral nutri-
Table I Nerve conduction studies of right ulnar nerve

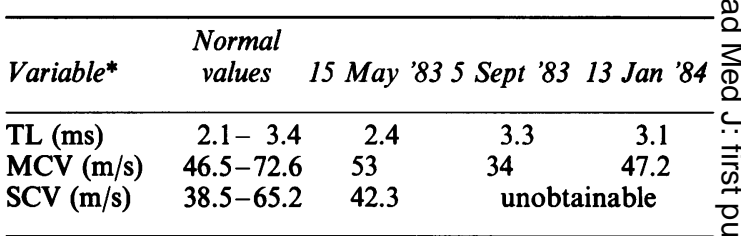

*TL $=$ terminal latency at wrist $\mathrm{MCV}=$ motor conduction velocity, elbow to wrist; $\mathrm{SCV}=$ sensory conduction $\frac{\text { ? }}{\vec{T}}$ velocity, finger to wrist.

tion was started in July. Within one week his appetite $\overrightarrow{\vec{\omega}}$ had improved and thereafter he steadily regained weight. His neurological symptoms gradually im- -00 proved and by November he was walking several miles?

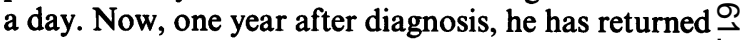
to work and his paraesthesiae has resolved although he still has difficulty with fine finger movements. Curren- $O$ tly he is maintained on $10 \mathrm{mg}$ of prednisolone daily and his eosinophil count is normal.

응
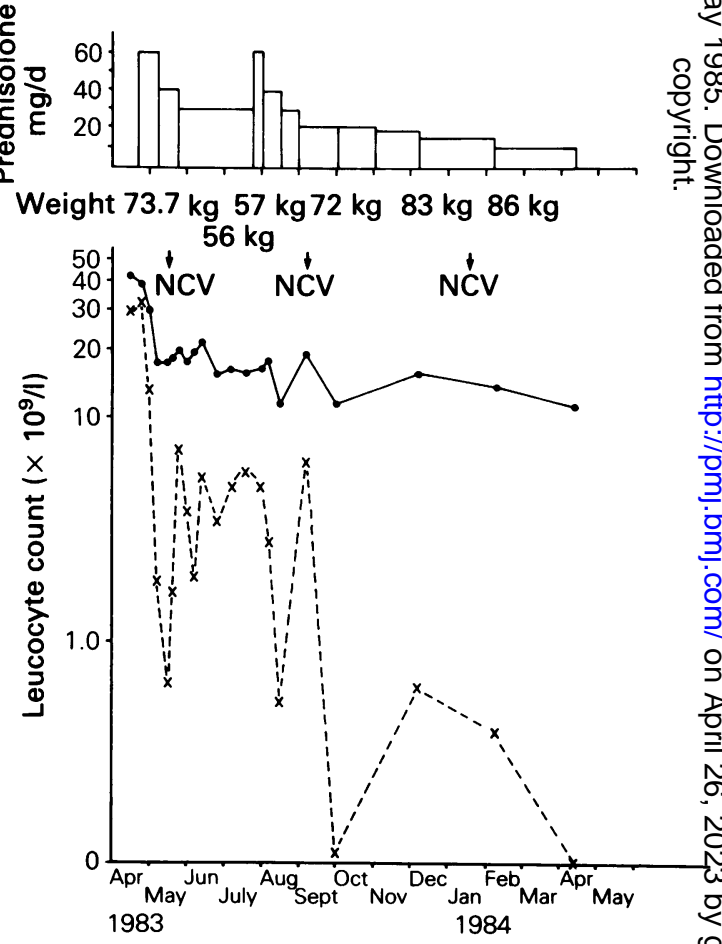

Figure 2 Total leucocyte and eosinophil count, and their response to steroid therapy in this patient with hypereosinophilic syndrome. $(O)$ Total white cell count; $(x)$ eosinophil $\square$ count; NCV; nerve conduction velocities. 


\section{Discussion}

This patient meets the diagnostic criteria for HES with persistent eosinophilia without demonstrable cause. This is a condition more common in males which usually presents between the third and sixth decades. In earlier reports of HES, peripheral neuropathy usually developed after cardiac or respiratory manifestation (Chusid et al., 1975; Dorfman et al., 1983). Five cases of peripheral neuropathy confirmed by nerve conduction studies have been described, the main features of which are summarized in Table II. Chusid et al. (1975), in their review of the literature, described four other cases; one of these had no neurological signs (Case Records, 1970), two had hyperreflexia and extensor plantars (Gardener-Thorpe et al., 1971; Yam et al., 1972) and the fourth had severe arterial disease (Novack et al., 1971). Our case would appear to be the first report of HES presenting with peripheral neuropathy, a feature which is an uncommon complication of the condition. Other features of HES, notably gastrointestinal involvement, subsequently developed in our patient. Of the five previously reported cases, three showed gradual improvement with corticosteroid therapy (Dorfman et al., 1983), whilst two (Chusid et al., 1975) had no response to corticosteroids or cyclophosphamide. While spontaneous improvement of the peripheral neuropathy may have occurred in our patient it seems more likely that corticosteroid therapy was of benefit in view of his eosinophil response.

The sural nerve biopsy showed no evidence of eosinophilic infiltration or arteritis in keeping with recent work which suggests that neural damage may be neurotoxin mediated. Eosinophils have been shown to contain neurotoxic substances responsible for the 'Gordon phenomenon' (Durack et al., 1979), a syndrome of muscular rigidity, ataxia and progressive paralysis, first described in laboratory animals following intraventricular injection of lymph node homogenates from patients with Hodgkin's disease (Gordon, 1933). Histologically, loss of Purkinje cells, vacuolation of the myelin sheath and axonal degeneration occurs, with peripheral nerve damage occasionally seen. Several eosinophil granule proteins have been purified and shown to reproduce the Gordon phenomenon. These include eosinophil-derived neurotoxin (Durack et al., 1981); eosinophil cationic protein and eosinophil protein X (Fredens et al., 1982). Eosinophil cationic protein also has specific toxic effects on the myocardial cell membrane (Spry et al., 1983b) and inhibits certain enzymes involved in mitochondrial respiration (Tai et al., 1982). We could detect no evidence of myocardial involvement in this case but it appears likely that the severe peripheral neuropathy may have been mediated by a circulating eosinophil neurotoxin.

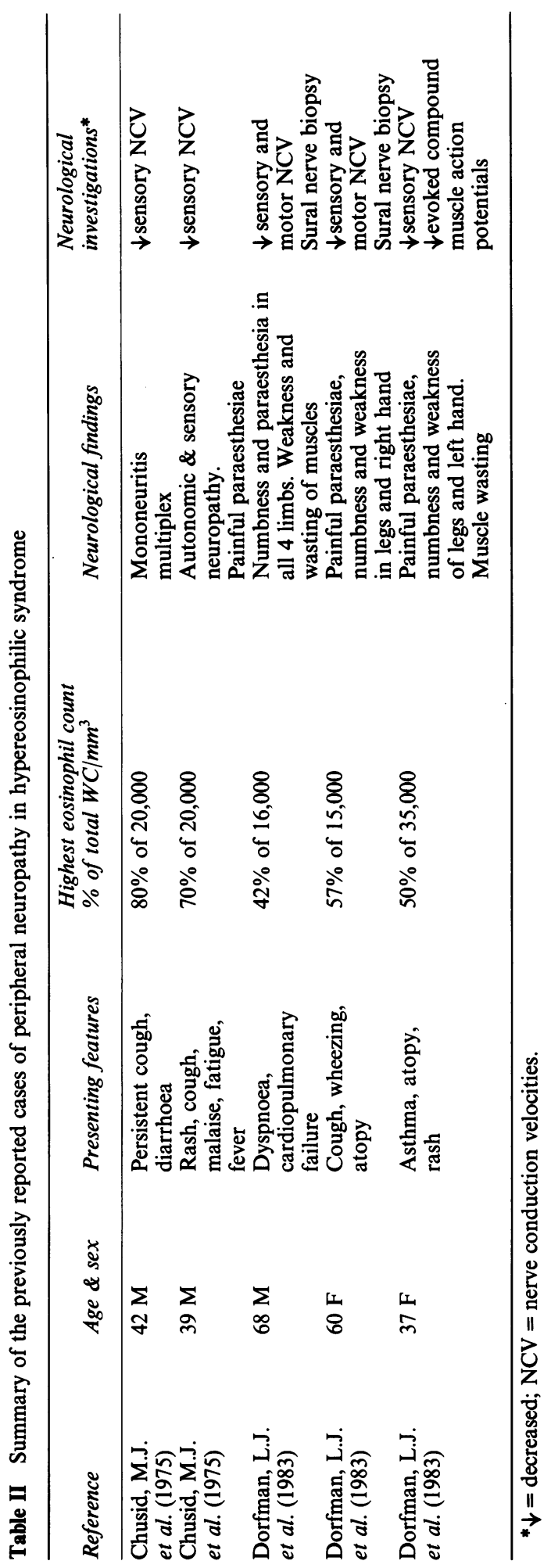




\section{References}

CASE RECORDS OF THE MASSACHUSETTS GENERAL HOSPITAL (1970). New England Journal of Medicine, 283, 476.

CHUSID, M.J., DALE, D.C., WEST, D.C. \& WOLFF, S.M. (1975). The hypereosinophilic syndrome. Medicine, 54, 1 .

DORFMAN, L.J., RANSOM, B.R., FORNO, L.S. \& KELTS, A. (1983). Neuropathy in the hypereosinophilic syndrome. Muscle and Nerve, 6, 291.

DURACK, D.T., ACKERMAN, S.T., LEOGERING, D.A. \& GLEICH, G.J. (1981). Purification of human eosinophil derived neurotoxin. Proceedings of the National Academy of Sciences of the United States of America, 78, 5165.

DURACK, D.T., SUMI, M.S. \& KLEBANOFF, S.J. (1979). Neurotoxicity of human eosinophils. Proceedings of the National Academy of Sciences of the United States of America, 76, 1443.

EWING, D.J. \& CLARKE, B.F. (1982). Diagnosis and management of diabetic autonomic neuropathy. British Medical Journal, 285, 916.

FREDENS, K., DAHL, R. \& VENGE, P. (1982). The Gordon Phenomenon induced by the eosinophilic cationic protein and eosinophil protein X. Journal of Allergy and Clinical Immunology, 70, 361 .

GARDENER-THORPE, C., HARRIMAN, D.G.F., PARSONS,
M. \& RUDGE, P. (1971). Loeffler's eosinophilic endocarditis with Balint's syndrome. Quarterly Journal of $\mathbb{\mathbb { D }}$ Medicine, 40, 249.

GORDON, M.H. (1933). Remarks on Hodgkin's disease. A. pathogenic agent in the glands and its application in diagnosis. British Medical Journal, 1, 641.

NOVACK, S.N., KUN, T.L. \& GOLDBERG, L.S. (1971). Arterial calcification associated with the hypereosinophilic system. Annals of Internal Medicine, 74, 99.

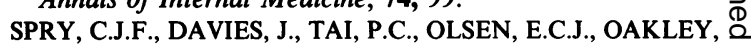
C.M. \& GOODWIN, J.F. (1983a). Clinical features of fifteen patients with the hypereosinophilic syndrome. Quarterly Journal of Medicine, 52, 1.

SPRY, C.J.F., TAI, P.C. \& DAVIES, J. (1983b). The cardiotox- $\overrightarrow{\vec{\omega}}$ icity of eosinophils. Postgraduate Medical Journal, 59, 147. ట్

TAI, P-C., HAYES, D.J., CLARK, J.B. \& SPRY, C.J.F., (1982). 흐 Toxic effects of human eosinophil secretion products on isolated rat heart cells in vitro. Biochemical Journal, 204, 75.

YAM, L.T., LI, C.Y., NECHELES, T.K. \& KATAYAMA, I. V (1972). Pseudoeosinophilia, eosinophilic endocarditis and $\vec{v}$ eosinophilic leukaemia. American Journal of Medicine, $5, \stackrel{\vec{N}}{\mathrm{~N}}$ 193. 